\title{
A SAÚDE NOS PARAMMETROS CURRICULARES NACIONAIS: CONSIDERAÇÕES A PARTIR DOS MANUAIS DE HIGIENE
}

\author{
Greicelene A. Hespanhol Bassinello
}

Resumo: Este artigo tem o objetivo de expor algumas reflexões sobre os Parâmetros Curriculares Nacionais, especificamente o tema transversal relacionado à saúde partindo de um breve histórico acerca dos manuais de higiene. O Ministério da Saúde ressalta o período escolar como fundamental para a promoção da saúde, já que as crianças e jovens que se encontram nas escolas vivem a oportunidade de obter cada vez mais a adequação de hábitos e atitudes que vão sendo revistos, dependendo da idade. Delimitamos como objeto de estudo os Parâmetros Curriculares Nacionais, que é o instrumento utilizado hoje para nortear o trabalho dos professores em relação à educação e saúde e o Ministério não dispõe de programa específico para o escolar.Em termos de metas a serem atingidas, enquanto o movimento higienista buscava legitimar uma categoria, o PCN é um instrumento de uma política educacional que consagrou uma intervenção na organização e cultura escolar.Conclui-se que a educação em saúde no âmbito do escolar deveria ser um processo interdisciplinar envolvendo os setores de saúde e educação.

Palavras-chave: Educação em saúde, saúde escolar, Parâmetros Curriculares Nacionais.

\section{THE HEALTH IN THE NATIONAL CURRICULUM PARAMETERS: CONSIDERATIONS STARTING FROM THE HYGIENE MANUALS}

Abstract: This article has the objective of exposing some reflections on the National Curriculum Parameters, specifically the traverse them related to the health starting from a brief historic concerning hygiene manuals. The Ministry of Health highlight the school period as an important point for the promotion of health. Since children and young people who goes to schools, has the opportunity to acquire better habits and attitudes that have been reviewed, depending on the age. We defined as studying object the National Curriculum Parameters, wich is the instrument used today to lead the teachers' work related to health education. The Ministry doesn't has as specific school program. In terms of goals to be reached, while the hygienic movement search for to legitimate a category. NCP is an instrument of educational policies, wich has consecrated an intervention in the organization and school culture. It is concluded that health education in school context should be a process interdisciplinary involving the sections of health an education.

Keywords: Health education; School health; National Curriculum Parameters 


\section{INTRODUÇÃO}

Olhar para o passado através de textos que nos proporcionam uma viagem pela história nos instiga a fazer comparações com os dias de hoje. Será que no decorrer da história só houve aperfeiçoamento e evoluções, ou certos procedimentos antigos nos traziam maiores esclarecimentos?

Minha viagem nesses últimos meses nas tardes de sexta-feira foi pela história da higiene, através dos manuais de higiene produzidos no final do século XIX e início do século XX, passando pelos médicos oitocentistas da Corte Imperial e chegando até os médicos higienistas da Faculdade de Saúde Pública de São Paulo, dirigidos à sociedade, pais e professores. Analisando os conteúdos expostos pensei na espécie de instrumentos hoje ao nosso alcance, com uma representação para a sociedade similar à dos manuais de higiene.

Tal curiosidade foi me tocando e me tomando ainda mais no momento em que coincidentemente fui chamada como enfermeira-docente para atuar em um projeto de intervenção num surto de pediculose em uma escola de ensino fundamental, que se encontrava sem estratégia de combate. Pensei: nada acontece por acaso.

Desses fatos surgiu a justificativa para o trabalho: quais as soluções apresentadas hoje para as questões relativas à higiene e a educação em saúde nas escolas? Quais manuais de orientação existem hoje? Quais os conteúdos e discurso existentes? Com que leituras podemos contar? Quais os atores envolvidos na elaboração e disseminação das informações?

Este artigo tem o objetivo de expor algumas reflexões sobre o assunto, partindo de um breve histórico acerca dos manuais de higiene e delimitando, como objeto de estudo, os Parâmetros Curriculares Nacionais, especificamente o tema transversal relacionado à saúde, que é o instrumento utilizado hoje para nortear o trabalho dos professores em relação à educação em saúde. 


\section{ACERCA DOS PARAMETROS CURRICULARES}

Os Parâmetros Curriculares (PCNs) se propõem a fornecer subsídios teóricos e metodológicos, ou seja, são orientações e referências estabelecidas pelo Ministério da Educação e Cultura (MEC) para cada etapa dos ensinos fundamental e médio no Brasil. Os PCNs de $1^{\mathrm{a}}$ a $4^{\mathrm{a}}$ série foram publicados em 1997; os de $5^{\mathrm{a}}$ a $8^{\mathrm{a}}$ série, em 1998; e os de ensino médio, em 1999. Interessa-nos, como fonte para o trabalho, os parâmetros relacionados ao ensino fundamental.

O Ensino Fundamental, gratuito na escola pública, com duração mínima de oito anos, tem por objetivo a formação básica do cidadão. É obrigatório a todas as crianças na faixa etária entre sete e catorze anos.

750.000 exemplares dos PCNS de $1^{\mathrm{a}}$ a $4^{\mathrm{a}}$ série foram impressos, sendo 723.600 distribuídos a professores da rede pública estadual e municipal e os restantes a outras instituições ligadas ao ensino. Quanto aos de $5^{\mathrm{a}}$ a $8^{\mathrm{a}}$ séries, 730.000 foram distribuídos para o público acima mencionado (BRASIL, 2004).

Os PCNs são organizados em 10 volumes, com um documento introdutório, seis documentos referentes às áreas de conhecimento: Língua Portuguesa, Matemática, Ciências Naturais, História, Geografia, Arte e Educação Física e três volumes referentes aos temas transversais, que têm como proposta a inserção nas escolas de questões sociais ou da sociedade brasileira, como ética, pluralidade cultural, orientação sexual, meio ambiente, saúde, trabalho e consumo.

\section{A SAÚDE CONTEMPLADA NOS PCNs}

Para lidar com as questões da sociedade brasileira o tema Saúde foi incorporado aos Parâmetros Curriculares Nacionais - PCNs e, segundo os especialistas, para que se possa refletir sobre educação e saúde sob uma ótica mais integradora.

Os PCNs começaram a ser elaborados no final de 1995, por especialistas do Ministério da Educação e Cultura, conjuntamente com abordagem e avaliação de professores acadêmicos, de várias instituições do país 
As origens da inserção dos cuidados com a saúde no ambiente escolar remontam ao final do século XIX, com o esforço de intelectuais e políticos para “conscientizar” a nação quanto aos avanços da civilização, que fez emergir os homens da ciência, dentre eles os médicos.

Buscando aumentar seu poder de atuação, legitimavam seus discursos através de prescrições, novos métodos e formas de controle social, com o propósito de intervir, como conselheiros e tutores, ocupando espaços importantes, sendo um deles a instituição escolar (HERSCHMANN, 1996). Os manuais adotados consagravam a doutrina de higiene como o principal ramo da ordem médica, apresentada como a arte de conservar e aperfeiçoar a saúde, visando à criação de sujeitos higiênicos, higienizados e higienizadores (GONDRA, 2003).

Segundo Rocha (2000), a escola no início do século XX foi um importante difusor de um modo de vida considerado civilizado. A re-configuração da escola neste processo de modernização e a inserção do campo da higiene como conhecimento escolar trouxeram à tona as estratégias de higienização, elaboradas pelos médicos higienistas.

Os manuais de higiene utilizados eram estruturados em capítulos destinados à sociedade, pais e professores e procuravam destacar os fundamentos e prescrições higiênicas a serem seguidos pela escola e seus agentes, contribuindo para a modernização pedagógica (GONDRA, 2000a).

Os PCNs constituem um conjunto de diretrizes capazes de nortear os currículos e seus conteúdos mínimos, ou seja, articular uma base nacional comum, ou referencial curricular comum para todo o país.

Neles consta que:

"Cada criança ou jovem brasileiro, mesmo de locais com pouca infraestrutura e condições sócio econômicas desfavoráveis, deve ter acesso ao conjunto de conhecimentos socialmente elaborados e reconhecidos como necessários para o exercício da cidadania para deles poder usufruir” (BRASIL, 1997a).

Os PCNs relacionados à Saúde procuram mostrar as possibilidades de trabalho com as quatro primeiras e as quatro últimas séries do ensino fundamental, organizando 
conteúdos, critérios de avaliação e orientações didáticas destinadas a professores do ensino fundamental.

Na elaboração deste trabalho optei, em termos de manuais de higiene, pela leitura dos estudos de Heloísa Rocha, que se concentram no conteúdo da obra do Dr. Afrânio Peixoto, médico, escritor e professor de higiene da Faculdade de Medicina do Rio de Janeiro, que publicou em co-autoria com o Doutor Graça Couto o manual Noções de Higiene (ROCHA, 2000a).

O manual consta de quatro partes: estudo sobre o corpo humano, condições gerais de saúde, condições especiais de saúde e agravos à saúde e meio de evitá-los. Na revisão do conteúdo, destacam-se a supressão do estudo sobre o corpo humano e o acréscimo de um capítulo introdutório ao estudo, dividido em três tópicos: a higiene; a saúde: condições gerais e especiais de saúde; e a doença: agravos à saúde e meios de os evitar.

Também recorremos à tese do Dr. Almeida Junior, elaborada no Instituto de Higiene de São Paulo e apresentada á Faculdade de Medicina, sendo posteriormente transformada em livro, com o intuito de difundir o conhecimento sobre higiene e bons hábitos, como as regras da higiene, o asseio corporal, a alimentação, a respiração e os exercícios físicos.

A escola, o exemplo do professor, as práticas de higiene e o conhecimento das questões relativas à higiene tornaram-se os elementos capazes de influir na atividade infantil (ROCHA, 2003a).

O modelo de intervenção pedagógica utilizado pelos médicos higienistas partia dos pressupostos de uma articulação entre o binômio educação e saúde e compreendia atuar na formação do professor, pela inclusão da disciplina de Higiene nos currículos das escolas normais; formação de agentes de saúde pública para atuação nas escolas; e produção de impressos destinados às crianças das escolas primárias e seus mestres.

Estavam incluídas a revista dos alunos pelos professores; a revista da escola pelos alunos; a observação e a correção, por parte dos professores, de condutas contrárias às prescrições higiênicas; a mensuração de peso, estatura e força física; e a indagação 
sobre a vida doméstica do aluno, para conhecer os hábitos das famílias; e a explicação dos porquês, como forma de reforçar bons hábitos (ROCHA, 2003b).

A subordinação do cuidado à infância a uma das áreas do curso médico, a higiene, com ações buscando evitar, atenuar, corrigir e conservar certos procedimentos buscava legitimar o discurso médico. A atuação na área escolar, implantando a higiene como conteúdo a ser efetivamente desenvolvido e trabalhado, só vinha a reforçar tal pretensão (GONDRA, 2000b).

Neste momento os especialistas do Ministério da Educação e Cultura se apropriam do tema e passam aos professores do ensino fundamental a responsabilidade pelo trabalho com a concepção de saúde que, segundo o manual, refere-se a informações sobre o funcionamento do corpo, descrição das características das doenças e do elenco de hábitos de higiene. A preocupação com o ensino da saúde tem trazido um desafio para a educação. Educar para a saúde significa formar hábitos de vida e mudança de atitudes.

O capítulo introdutório do manual traz a concepção do termo saúde, incluindo a abordagem sobre a legislação que trata do assunto e inicia uma proposta de articulação entre educação e saúde: “Ensinar saúde ou educar para a saúde?”.

Bem próximo do discurso higienista, talvez sob outro formato, o manual PCN Saúde menciona que a criança no início da vida escolar traz consigo a valoração de comportamentos favoráveis ou desfavoráveis à saúde oriundos da família e outros grupos de relação mais direta, ou seja, a conformação de hábitos (legitimados por esses grupos) não necessariamente considerados adequados. Assim sendo, a escola passa a assumir o papel de promotora de mudanças favoráveis para seus membros (BRASIL, 1997b).

Os objetivos gerais para a saúde no ensino fundamental são: conscientizar os alunos sobre o direito à saúde; compreender que a condição de saúde é produzida nas relações com o meio em que vivem; conhecer e utilizar formas de intervenção individual e coletiva sobre os fatores que agem sobre a saúde; e fazer com que os alunos adotem hábitos de autocuidado, respeitando as possibilidades e limites do próprio corpo. 
Os conteúdos a serem trabalhados com os alunos foram organizados em dois blocos: autoconhecimento para o autocuidado e vida coletiva, destinados ao trabalho pedagógico nos primeiro e segundo ciclos do ensino fundamental.

O bloco de conteúdo - autoconhecimento para o autocuidado - refere-se ao conhecimento do funcionamento do corpo humano, para o aluno aprender a se cuidar e identificar semelhanças e diferenças. A higiene corporal aparece como condição para a vida saudável e deve ter início na infância, sendo destacada a importância de sua prática sistemática.

A orientação é executar junto com a criança os procedimentos passíveis de orientação no ambiente escolar, como lavagem das mãos e escovação de dentes. Sugerese o não empobrecimento do conteúdo, em condições adversas, enfatizando também que a ausência de sanitários ou água potável não pode ser encarada como fator imobilizante.

A alimentação surge como essencial para o crescimento e o desenvolvimento da criança, sendo que o consumo de alimentos inadequados é um problema a ser enfrentado de acordo com as particularidades de cada realidade. A associação direta entre a higiene e alimentação precisa ser enfatizada e a identificação da água, alimentos e objetos contaminados, como fontes de doença, promove o preparo do aluno para uma alimentação saudável.

Um cuidado importante a ser tomado pelo educador, segundo o manual, é o de evitar assumir linhas prescritivas, como se o objetivo fosse normatizar a vida privada do aluno e padronizar condutas.

Segundo o manual:

\footnotetext{
"Na escola é possível o desenvolvimento de atitudes de solidariedade e cooperações nas pequenas ações do cotidiano como, por exemplo, a colaboração na conservação da limpeza do ambiente, incentivando para que estas atitudes se estendam no âmbito familiar e ambientes públicos, para que tal responsabilidade se transforme em prática de vida” (BRASIL, 1997b).
}

Para a vida coletiva, as crianças são, sem dúvida, bons agentes de saúde, e o professor deve ocupar-se dos riscos intimamente relacionados com a infância, a saber: doenças transmissíveis; acidentes domésticos e de trânsito; os decorrentes da violência social, como maus-tratos; acidentes com armas de fogo; violência sexual e os associados ao trabalho infantil. 
No critério de avaliação do aluno, o desejado para o final do segundo ciclo é que ele seja capaz de perceber sensações de desconforto e de dor, bem como proceder a ações de higiene corporal, de maneira autônoma. O professor deve avaliar ações básicas, como a lavagem das mãos antes das refeições e após o uso do banheiro, o banho diário, o cuidar de cabelos e unhas, a escovação dos dentes e o uso adequado dos sanitários.

Para o trabalho com os alunos do terceiro e quarto ciclos sugere-se maior dedicação aos fatores externos, que são os principais agravos à saúde. Aí se incluem os acidentes extradomiciliares e violência social. Para o sexo masculino menciona-se os acidentes de trânsito e, para o feminino, a gravidez na adolescência. Quanto à higiene bucal, no geral são altos os índices de cárie dentária nesta faixa etária no Brasil (BRASIL, 1998).

Os temas abordados devem permitir a construção da identidade e da auto-estima, os cuidados com o corpo, nutrição, a valorização dos vínculos afetivos e a negociação de comportamentos apropriados para o convívio social.

A higiene corporal é, portanto, condição crucial para a vida saudável. A aquisição de bons hábitos tem início na infância, contudo não é o enfoque principal no terceiro e quarto ciclos, pois presume-se que essa prática já tenha sido incorporada ao cotidiano. O estabelecimento de relações entre o autocuidado e o convívio social deve ser prelecionado e buscado.

\section{REFLEXÕES SOBRE CENÁRIOS, ATORES, CENAS E MANUAIS.}

A meu ver, a integração entre saúde e educação significa a articulação entre os setores envolvidos e o engajamento de autoridades da saúde e da educação, como professores, administradores de escola, pais e prestadores de serviços de saúde e a comunidade para o desenvolvimento de atividades envolvendo a saúde na escola.

O Ministério da Saúde (BRASIL, 2002) apóia-se no discurso que ressalta o período escolar como fundamental para a promoção da saúde, já que as crianças e jovens que se encontram nas escolas vivem a oportunidade de obter cada vez mais a adequação de hábitos e atitudes que vão sendo revistos, dependendo da idade. 
Contudo, o próprio Ministério, que é o responsável pela elaboração dos Programas de Saúde e pela normatização das ações e serviços em nível nacional, não dispõe de programa específico para a atuação na área da saúde do escolar. Quando ocorrem nos ambientes escolares tais intervenções, pelos profissionais de saúde, são isoladas, intervencionistas e verticalizadas, além de seu cunho assistencialista. Nos dias de hoje raramente os profissionais de saúde têm acesso à escola, ficando a tarefa de educar para a saúde exclusivamente nas mãos dos professores.

No contexto escolar o manual faz referência ao conceito de promoção da saúde com respeito às possibilidades e aos limites do corpo, do intelecto e das emoções, da participação social e do estabelecimento de alianças.

A terminologia é bastante utópica para um país de grande diversidade regional, em que o censo escolar observa o predomínio da escola pública. O Brasil tem 57 milhões de alunos matriculados, dos quais 35 milhões freqüentam o ensino fundamental, em 212 mil escolas (INEP, 2003).

Vale lembrar, em relação à criança brasileira, em que condições históricas e socioeconômicas ela tem vivido fora do universo escolar?

Para Bonamino e Martinez (2002), o que poderia ser um conjunto de conteúdos mínimos e obrigatórios para o ensino fundamental transformou-se num tema complexo, denso e com orientações axiológicas, metodológicas, critérios de avaliação e conteúdos específicos para todas as áreas de ensino e para serem aplicados de modo transversal na escola.

Pregam Frigotto e Ciavatta (2003) que os anos 90 registram a presença de organismos internacionais que entram em cena em termos organizacionais e pedagógicos, marcados por grandes eventos, assessoria técnica e farta produção documental.

Fico imaginando qual professor brasileiro (vigilante e treinado?) de ensino fundamental é capaz de ministrar suas tarefas, incorporar noções de saúde e tratar de temas, trabalhando com noções e conceitos? 
Referindo-se a essa questão, os relatores dos PCNs relatam que não é pressuposto para a saúde a existência do professor especialista, pois o trabalho pedagógico terá como enfoque principal a saúde e não a doença.

Como o professor constrói e se apropria de conhecimentos, quem é este profissional da educação capaz de lidar com diversos temas, incluindo um complexo tratado de questões sociais?

A saída encontrada para esse impasse foi a mudança na formação dos professores, para que desenvolvam competências profissionais para atender as novas concepções de educação escolar e do papel do professor. Tem de ser em nível superior, o que deu início aos cursos seqüenciais hoje denominados normal superior, com a duração de dois anos letivos, com o programa parâmetros em ação para formação continuada no interior da escola e a melhoria da prática dos profissionais já em exercício em sala de aula (PRADO, 2000).

Nos diversos momentos históricos pelos quais passou a escola observamos que ocorreram diversas formas de controle sobre a instituição, o ensino, os docentes e aquilo por eles é ensinado.

Assim como os manuais de Higiene ou as intervenções higienistas na escola procuraram legitimar a ordem médica, os PCNs, através de suas diretrizes, procuram legitimar uma política pública de educação ou o controle do estado sobre o que as escolas devem ensinar.

Minha experiência em relação às políticas educacionais é nova. No entanto, após leitura sobre o tema vejo o quanto os integrantes da comunidade educacional ficam distantes das estratégias recomendadas pelo governo, o pouco que existe para capacitação relevante e efetiva dos professores e material de educação em saúde para desenvolverem o seu trabalho.

Para Souza et al (1999):

\footnotetext{
“A definição e o controle do Estado sobre o que as escolas devem ensinar, verificado em todos os sistemas nacionais do ensino elementar constituídos a partir do século XIX podem ser vistos como uma tentativa do estado para manter o controle ideológico sobre a sociedade e implementar com o processo de homogeneização cultural mediante a ação da escola.”
} 
A reflexão promovida pela leitura relevante para os dois temas, aliada às lições aprendidas durante minhas aulas temáticas, permite concluir que os conteúdos dos manuais da era da higiene não diferem muito do que hoje é proposto pelos PCNs visando o tema saúde.

Apesar dos contextos serem diferentes, existem similaridades na intenção prévia de se trabalhar dentro do binômio saúde e educação, como o estudo sobre o corpo humano, os aspectos de higiene corporal, as condições de saúde e doença. As propostas são muito parecidas, os discursos e as prescrições também, não obstante os especialistas do MEC sugerirem evitar linhas prescritivas.

É interessante notar, após a leitura dos manuais e parâmetros, que o modelo pedagógico instituído pelos higienistas consistia das mesmas tarefas que hoje devem ser competências das escolas primárias ou de ensino fundamental, como eliminar atitudes viciosas e adotar hábitos saudáveis. Vejo semelhanças nas atividades de asseio corporal a serem executadas com os alunos e nas chamadas de solidariedade, que nada mais representam que a conservação da limpeza da escola, ou a revista da escola pelos alunos.

Quando falamos em condutas contrárias às prescrições higiênicas, o manual cita a postura física inadequada e os agravos ocasionados pelo uso de drogas. Também as indagações sobre a vida doméstica e a explicação dos porquês representam todo um trabalho sugerido no bloco de conteúdos vida coletiva.

O PCN Saúde é caracterizado como material de apoio ao trabalho docente, com conteúdo abrangente e ambicioso, em vista da diversidade de ambiente e atores, a precariedade do ensino e a formação dos professores.

Assim, os manuais de higiene foram construídos a partir de realidades concretas, de intervenções ditas pedagógicas, sendo o programa de ensino de higiene incluído nas escolas normais existentes para a formação dos professores. O conjunto de práticas foi instituído no cotidiano escolar, enquanto que os PCNs foram construídos fora da realidade escolar, produzidos por especialistas distanciados das condições concretas da realidade brasileira. 


\section{CONSIDERAÇÕES FINAIS}

Sem a intenção de desenvolver um tratado ou um estudo comparado dos manuais de higiene e das ações do movimento higienista no âmbito escolar, este trabalho, em contrapartida, foi uma proposta de verificar o que existe de concreto hoje nas escolas, em termos de investimento em saúde.

Em termos de metas a serem atingidas, enquanto o movimento higienista buscava legitimar uma categoria, o PCN é um instrumento de uma política educacional que consagrou uma intervenção na organização e cultura escolar.

A educação em saúde no âmbito escolar deveria ser um processo interdisciplinar e intersetorial, com programas de fomento à saúde para o pessoal da educação e de assessoramento, envolvendo os setores de saúde e educação. O discurso emergente de escolas que promovem saúde é despertar a necessidade de mudanças no olhar e na prática de todos os profissionais, que continuam persistindo no erro de atuar isoladamente, prescrevendo regras para a população brasileira (ROCHA, MARCELO e PEREIRA, 2002).

\section{REFERÊNCIAS}

BONAMINO, A; MARTINEZ, S.A. Diretrizes e Parâmetros Curriculares Nacionais para o Ensino Fundamental: a participação das instâncias políticas do Estado. Ed. Soc, Campinas, v.23, n.80, p. 386-400, set. 2002.

BRASIL. Ministério da Saúde. A Promoção da Saúde no contexto escolar. Rev. Saúde Pública, São Paulo, v.36, n.2, p. 533-5, 2002.

- Secretaria de Educação Fundamental. Parâmetros Curriculares Nacionais: Introdução aos Parâmetros Curriculares Nacionais.Brasília: MEC/SEF, 1997a.

- Secretaria de Educação Fundamental. Parâmetros Curriculares Nacionais: Saúde.Brasília: MEC/SEF, 1997b.

- Secretaria de Educação Fundamental. Parâmetros Curriculares Nacionais: Saúde.Brasília: MEC/SEF, 1998.

Secretaria de Educação Fundamental. Parâmetros Curriculares Nacionais.

Disponível em http//: www.mec.gov.br. Acesso em 10.06.2004.

(C) ETD - Educação Temática Digital, Campinas, v.6, n.1, p.34-47, dez.2004 - ISSN: 1676-2592. 
FRIGOTTO,G; CIAVATTA, M. Educação Básica no Brasil na década de 1990: subordinação ativa e consentida à lógica do mercado. Ed. Soc, Campinas, v.24, n.82, p. 93-130, abril 2003.

GOIS JUNIOR, E; LOVISOLO, H.R. Descontinuidades e continuidades no movimento higienista no Brasil do século XX. Revista Brasileira de Ciências do Esporte, v.25, n.1, p.41-54, setembro 2003.

GONDRA, J.G. Artes de Civilizar: medicina, higiene e educação escolar na Corte Imperial. São Paulo, 2000. Tese (Doutorado) Faculdade de Educação, Universidade de São Paulo, 2000a.

A sementeira do porvir: higiene e infância no século XIX. Edu. Pesq, São Paulo, v.26, n.1, p. 99 - 117, jan/jun. 2000b.

Homo hygienicus: educação, higiene e a reinvenção do homem. Caderno Cedes, Campinas, v.23, n. 59, p. 25-38, abril 2003.

HERSCHMAN, M. Entre a insalubridade e a ignorância. A construção do campo médico e do ideário moderno no Brasil. In: HERSCHMANN, M; KROPF, S.P; NUNES, C. (orgs.). Missionários do progresso: médicos, engenheiros e educadores no Rio de Janeiro - 1870 - 1937. Rio de Janeiro: Diadorim, 1996.

INEP. Instituto Nacional de Estudos e Pesquisas Educacionais Anísio Teixeira. Censo Escolar. Disponível em http: //www.inep.gov.br. Acesso em 29/05/2004.

PRADO, I.G.A. O MEC e a Reorganização Curricular. São Paulo Perspectiva, São Paulo, v.14, n.1,p. 94-97, jan/mar. 2000.

ROCHA, D.G.; MARCELO, V.C.; PEREIRA, I.M.T. Escola promotora de Saúde: uma construção interdisciplinar e intersetorial. Rev. Bras. Cien. Desen. Hum, São Paulo, v.12, n.1, p.57-63, 2002.

ROCHA, H.H.P. Prescrevendo regras de bem viver: cultura escolar e racionalidade científica. Caderno Cedes, Campinas, v.20, n.52, novembro 2000.

A higienização dos costumes: educação escolar e saúde no projeto do Instituto de Higiene de São Paulo (1918-1925). Campinas, SP: Mercado de Letras, São Paulo: Fapesp, 2003 a.

Educação Escolar e Higienização da Infância. Caderno Cedes, v.23, n.59, p. 39-56, abril 2003b.

SOUZA, R.F.de; BORGHI, R.F; ONOFRE, M.R.; CAMARGO, L.T. Guias Curriculares: materiais de orientação docente ou de controle do Estado? Revista Brasileira de Estudos Pedagógicos, v.80, n.195, p.233-243, maio/ago. 1999. 


\section{Agradecimentos}

À Professora Heloisa Helena Pimenta Rocha pela forma competente que ministrou a disciplina Seminários Temáticos da História da Educação, ensinamentos com os quais construí este trabalho. 